\title{
O "Tratado de Arquitectura" de Antônio Rodrigues e a construção do saber teórico do arquiteto no século XVI em Portugal
}

\author{
Sarah Dume ${ }^{1}$
}

DOI 10.20396/eha.vil4.3487

A partir das últimas décadas do século XX, historiadores da arte tem se curvado em prol de um estudo apurado das fontes artísticas legadas por artistas e arquitetos portugueses, as quais muitas ainda se encontram pronta a serem descobertas nos inúmeros arquivos e bibliotecas públicas e privadas espalhadas pelo mundo. Desta forma, propõe se nesta comunicação discutir aquele que é reconhecido como o primeiro tratado de arquitetura português ${ }^{2}$ : o manuscrito de Antônio Rodrigues intitulado "Tratado de Arquitectura" (1576), depositado na Biblioteca Nacional de Portugal como o códice $3675^{3}$ e o espaço de sistematização da arquitetura enquanto saber teórico no momento de produção do documento.

O manuscrito redigido em Portugal durante o governo de D. Sebastião (1554-1578) proporciona uma compreensão sobre o do cenário profissional em que Rodrigues estava inserido como mestre de obras e fortificações do reino durante o terceiro quartel do século XVI, e quais saberes o levaram a ser reconhecido enquanto profissional artífice da construção.

Antônio Rodrigues fizera parte das transformações ocorridas na compreensão acerca do conceito de arquiteto, bem como estivera entre os profissionais da construção que efetivaram as mudanças nos estilos e nos modos de construir na corte portuguesa do século XVI. A busca pela arquitetura "ao romano"4 faz parte da conjuntura que constituíra o desígnio do Estado Moderno português nos primeiros anos dos Quinhentos, aliando os preceitos da arte dita antiga para com os intentos régios, recorrendo à exteriorização do poder político e expansão do reino por meio da

\footnotetext{
1 Graduada em História pela Universidade Metodista de Piracicaba. Atualmente é mestranda em História da Arte pela Universidade Estadual de Campinas, contando com o apoio da Fundação de Amparo a Pesquisa do Estado de São Paulo (Processo 2019/11512-9) e membro do grupo ORNAMENTA (Grupo de Estudos Avançados de Arte Sacra - UNICAMP).

2 Atribuído e datado pelo historiador da arte Rafael Moreira em sua dissertação de mestrado. MOREIRA, Rafael, Um tratado português de Arquitectura do século XVI (Tese de mestrado, Universidade Nova de Lisboa, 1982), in AAVV, Colectânea de Estudos - Universo Urbanístico Português, 1415-1822, Lisboa, Comissão Nacional para as Comemorações dos Descobrimentos Portugueses, 1998.

3 RODRIGUES, António, ca 1525?-1590. [Tratado de arquitectura] [1575-1576]. - [1] f., f. 3-45, f. [46-67], enc. : il. ; 29 cm. Disponível em: http://purl. $\mathrm{pt} / 27112$.

4 Sobre a arquitetura "ao romano", ver mais em: CRAVEIRO, Maria de Lurdes. A arquitetura ao romano; in; RODRIGUES, Dalila (coord). A arte portuguesa: da Pré-História ao século XX, 2009.
} 


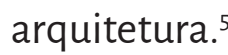

A necessidade da ampliação de defesas de territórios no século XVI demandara transformações nas formas de construir do período, abrindo espaço para a introdução do ideal clássico italiano e sobre suas formas de fortificar. A ciência da construção passa a circular em meio a corte, transpassando as paredes dos conventos e monastérios, atendendo às novas demandas que emergiram como resultado das navegações. ${ }^{6}$ Ao reinado de D. João III (1521-1557), dá-se o início ao movimento de reformulação das praças fortificadas do Norte da África conquistadas ao início do século XVI que resultará numa junta de especialistas na arte militar e da circulação destes entre Portugal e o norte africano.7 Segundo Rafael Moreira, essa junta teria sido encabeçada por D. João III, seguido de seu irmão o infante D. Luís. Ao corpo da junta, encontrava-se também o arquiteto Miguel de Arruda (1500-1563), o qual fora incumbido de acompanhar ao norte africano o arquiteto italiano Benedetto de Ravena (1485-1556), acompanhados de Diogo de Torralva (1500-1566) e João de Castilho (14701552), reconhecidos como os mais célebres entre os profissionais da arquitetura renascentista portuguesa.

Durante esse período observa-se o desenvolvimento do processo de incentivo à ida de artistas portugueses em busca do saber da linguagem clássica da arquitetura em território italiano ${ }^{8}$, bem como a vinda de profissionais estrangeiros conhecedores de tais artes, e, em uniformidade a dimensão do movimento de trabalho gerado com a circulação destes profissionais, instaura-se neste momento um órgão central que gerirá, a partir daí, o empreendimento das construções fortificadas nessa região e se utilizará da experiência e do saber italiano para o aprimoramento da defesa de Portugal. ${ }^{9}$

Os profissionais portugueses que houvessem de obter conhecimento acerca da arte de edificar em território italiano, teriam então, por compromisso, que utilizar deste saber em prol das projeções modernas realizadas em Portugal. Este é o caso de Antônio Rodrigues, que apresenta, por meio do códice 3675, um conhecimento alinhado às prerrogativas da arquitetura clássica presente em Itália. ${ }^{10}$

\footnotetext{
5 MOREIRA, Rafael. Arquitectura: Renascimento e classicismo. História da Arte Portuguesa, v. 2, p. 302-375, 1995.

6 TAVARES, Domingos; XAVIER, João Pedro. António Rodrigues: renascimento em Portugal. Dafne, 2007, p.32.

7 CARITA, Rui. A defesa do Atlântico nos séculos XV e XVI. A arquitectura militar na expansão portuguesa. Porto: Maiadouro, 1994 , p. 117-118.

8 CORREIA, Jorge. "...determino mandar um destes italianos [...] para melhor poderdes efectuar essa fortificação". In: Arquitectos italianos em Portugal. MARNOTO, Rita. (Org. Dossiê) Arquitectos italianos em Portugal. Estudos Italianos em Portugal, v. 12, p. 149-164, 2017.

9 CARITA, op.cit, p.118.

10 MOREIRA, Rafael. A escola de arquitectura do Paço da Ribeira e a Academia de Matemáticas de Madrid. Relações Artísticas Entre Portugal e Espanha na Época dos Descobrimentos, p.67, 1987.
} 
A ascendência profissional dos arquitetos quinhentistas portugueses estava também atrelada ao fato de estes indivíduos serem parte de famílias de profissionais artífices que promoviam entre seus membros o contato com profissionais da arquitetura na Península Itálica por meio de viagens aos estaleiros italianos de construções, como demonstra Rafael Moreira nos casos das famílias Álvares e Ruão, cernes de grandes arquitetos do renascimento português:

"Em primeiro lugar, é de salientar uma estrita endogenia na transmissão de saberes: além do caso de Baltasar e Afonso Álvares, os mais importantes arquitectos da época ou pertenciam a famílias já ligadas ao ofício ou fundaram eles próprios a sua própria dinastia. João de Ruão foi pai do arquitecto Jerónimo de Ruão, do engenheiro Simão de Ruão (c. 15351570), que após uma significativa estadia em Itália era, em 1567, encarregado da concepção de um sistema defensivo para a Foz do Douro, antes de partir para a Índia no séquito do vice-rei D. Luís de Ataíde (Moreira, 1981, p. 285), e do licenciado João de Ruão, juiz-de-fora com carta passada pelo Desembargo do Paço e nomeado para a vila de Freixo, mas julgado capaz, em 1570, de dirigir as obras do Forte da Barra de Viana do Minho (Moreira, 1994, p.62)." (...)

Não se pode afirmar que o prestígio como arquiteto adquirido por Rodrigues possa ter ocorrências em sua ascendência, pois, até o momento, de nada se sabe sobre sua genealogia, somente sua participação profissional e trechos de seu percurso enquanto mestre de obras e de fortificações do reino português na segunda metade do XVI. ${ }^{12}$ Segundo Rafael Moreira, há notícias de sua passagem por terras italianas entre os anos de 1560 e 1564, ponto esse que se torna culminante na compreensão a respeito de sua formação e das inspirações teóricas de grandes tratadistas da época que se encontram entre as linhas de seu "Tratado de Arquitectura". ${ }^{33}$

É de grande importância, juntamente com as viagens desses profissionais a Itália, destacar a circulação de tratados de arte e arquitetura que se dissiparam em inúmeras edições na Península Ibérica durante todo o século XVI. A sistematização da arquitetura enquanto ciência acarretara na introdução, divulgação e circulação da produção literária artística entre Espanha e Portugal, fazendo com que os arquitetos régios da Península Ibérica tivessem contato com os cânones pressupostos da linguagem clássica da arquitetura. ${ }^{14}$ É o caso do pioneiro espanhol Diego de Sagredo, onde, por meio de "Medidas del Romano" (1526) produz o primeiro tratado de arquitetura da Península

\footnotetext{
11 MOREIRA, op.cit, p.397.

12 TAVARES, op.cit, p.32.

13 MOREIRA, Rafael. A escola de arquitectura do Paço da Ribeira e a Academia de Matemáticas de Madrid. Relações Artísticas Entre Portugal e Espanha na Época dos Descobrimentos. Edições Minerva, Coimbra, 1987, p.67.

14 LOEWEN, Andrea Buchidid. Estilo desornamentado, arquitetura-chã: alguns aspectos do renascimento na Península Ibérica. Pós. Revista Do Programa De Pós-Graduação Em Arquitetura E Urbanismo Da FAUUSP, v. 18, n. 30, 2011, p.61-62.
} 
Ibérica, destacando em seu conteúdo as ordens arquitetônicas, suas proporções e ornamentos, de forma a constituir-se como um manual aos interessados nas formas da arquitetura antiga ${ }^{15}$, utilizando-se de Leon Battista Alberti para atestar seus apontamentos. ${ }^{16}$

Como em Sagredo, apesar de posterior, o manuscrito de Antônio Rodrigues se insere no círculo de produções teóricas artísticas que se pautaram nos modelos da vanguarda da tratadística italiana, porém, por meio das bases de Sérlio e Vignola. ${ }^{17}$

O "Tratado de Arquitectura" (1576) de Antônio Rodrigues

Antônio Rodrigues relegou ao campo dos estudos da história da arquitetura um manuscrito no qual professa, em 42 fólios, lições voltadas à instrução do aprendiz da arte de projetar. O documento apresenta-se como um material teórico que demonstra ser designado para objetivos didáticos, buscando que seu leitor, interessado e provavelmente aprendiz da arte da construção, compreenda as bases necessárias para a feitura de sítios, muralhas e moradas. Incompleto em algumas páginas, sente-se a ausência da dedicatória e a parte inicial do prólogo, das definições de geometria 2, 3, 4, 5 e 6, bem como das proposições 9, 33, 46 e 47 na parte voltada ao estudo da perspectiva pelo autor do texto. Percebe-se também que os fólios textuais dedicados às construções abaluartadas, desenhadas em aquarela ao final do documento, encontram-se ausentes do corpo do texto.

Para além de um manuscrito voltado à arquitetura, o documento demonstra preocupações voltadas ao clima e à geografia dos sítios a que se refere, bem como das técnicas construtivas em diversificados tipos de materiais.

O tratado de Rodrigues apresenta-se como um material didático que pode ter sido desenvolvido em prol da aprendizagem da arquitetura nos ambientes de ensino que emergiram na corte portuguesa, como por meio das aulas ocorridas no Paço da Ribeira durante o governo de D. Sebastião, dedicadas ao ensino de cosmografia, geometria e arquitetura - esta última, ministrada pelo próprio autor do "Tratado de Arquitectura" - aos aprendizes da arte da edificação militar ${ }^{18}$ como também do aperfeiçoamento dos aprendizes na arte do desenho. As demandas geradas pelo expansionismo abriram espaço para o desenvolvimento da ciência do desenho' ${ }^{19}$ e da sistematização

\footnotetext{
15 LOEWEN, op.cit, p.60 apud (BURY, 1989, p. 43).

16 LOEWEN, op.cit, p. 59.

17 XAVIER, João Pedro. Arquitectura e Ciência - Antônio Rodrigues. Ciência em Portugal - Personagens e episódios. Porto, 2004, p.1

18 MOREIRA, ibidem, p.67.

19 Sobre a ciência e o uso do desenho na projeção dos aparatos de defesa portuguesas entre os séculos XVI e XIX, recomenda-se: BUENO, Be-
} 
do saber de edificar, saberes os quais serviram em prol da organização de defesa e resultaram em novas formas de se projetar as construções fortificadas.

Segundo Beatriz Picolotto Bueno,

O desenho como instrumento de raciocínio e síntese esteve na base da ascensão da Arquitetura ao contexto das Artes Liberais, tendo Leon Batista Alberti-De re aedificatoria (1452) - como principal mentor. Esta ferramenta de trabalho permitiu que um conceito de edificação ("idéia"), mentalmente arquitetado a priori, fosse representado graficamente, resultando numa construção situada no lugar mais adequado e edificada proporcionadamente e firme, com orçamento viável às condições financeiras do comitente. Os projetos, uma vez aprovados pelos superiores hierárquicos, orientavam o trabalho dos mestres dos mais variados ofícios, fundamentando a arrematação de cada uma das partes da obra e permitindo supervisionar-lhes o andamento. Ao mesmo tempo, estas folhas de papel atreladas a ofícios manuscritos permitiam alinhavar conversas de longa de distância, num império de proporções planetárias cuja gestão emanava de Lisboa. ${ }^{20}$

O rigor necessário para a projeção dessas novas formas de defesa coloca em evidência o papel desses profissionais, que, apoiados no saber científico, desenvolveram métodos e teorias que revelam os intentos do Império em meio a uma nova conjuntura política, econômica e social ocorrente em Portugal ao longo do século XVI. O "Tratado de Arquitectura" de Antônio Rodrigues pode ser compreendido neste contexto como um reflexo das necessidades do processo de defesa territorial recorrentes em Portugal no século XVI, propiciando ao estudo da teoria artística meios de compreensão das consequências dos processos urbanizatórios e defensivos dos territórios portugueses, sendo o único a demonstrar os métodos de representação científicos da arquitetura, como também teorias e modelos circulantes na Portugal quinhentista sobre a arte do desenho de edificações.

Os artistas e suas obras permitiam que a sociedade portuguesa do século XVI entrasse em contato com realidades dadas como pressupostos para um fazer artístico, bem como, utilizar-se desses pressupostos em prol da expansão de seu território. Enfim, tais escritos artísticos são legados dos artistas ao longo do tempo e que nos proporcionam uma maneira de compreender de que forma a arte servira de instrumento para diferentes propósitos ao longo da história, cumprindo papéis nas mais diversificadas camadas sociais as quais fora produzida e tivera circulação.

atriz P. Siqueira. Desenho e desígnio: o Brasil dos engenheiros militares. São Paulo: Edusp, 2000. 


\section{Referências Bibliográficas}

BUENO, Beatriz Piccolotto Siqueira. Com as mãos sujas de cal e de tinta, homens de múltiplas habilidades: os engenheiros militares e a cartografia na América portuguesa (séc. XVI-XIX). Navigator: subsídios para a História Marítima do Brasil, Rio de Janeiro, v. 7, n. 14, p. 10, 2011.

CARITA, Rui. A defesa do Atlântico nos séculos XV e XVI. A arquitectura militar na expansão portuguesa. Porto: Maiadouro, 1994.

CORREIA, Jorge. "...determino mandar um destes italianos [...] para melhor poderdes efectuar essa fortificação". In: Arquitectos italianos em Portugal. MARNOTO, Rita. (Org. Dossiê) Arquitectos italianos em Portugal. Estudos Italianos em Portugal, v. 12, p. 149-164, 2017.

LOEWEN, Andrea Buchidid. Estilo desornamentado, arquitetura-chã: alguns aspectos do renascimento na Península Ibérica. Pós. Revista do Programa de Pós-Graduação em Arquitetura e Urbanismo da FAUUSP, v. 18, n. 30, p. 56-69, 2011.

MOREIRA, Rafael. Arquitectura: Renascimento e classicismo. História da Arte Portuguesa, v. 2, p. 302-375, 1995.

MOREIRA, Rafael. A escola de arquitectura do Paço da Ribeira e a Academia de Matemáticas de Madrid. Relações Artísticas Entre Portugal e Espanha na Época dos Descobrimentos. Edições Minerva, Coimbra, 1987.

RODRICUES, António. Tratado de arquitectura. [1575-1576]. - [1] f., f. 3-45, f. [46-67], enc. : il. ; 29 cm. Disponível em: http://purl.pt/27112.

TAVARES, Domingos; XAVIER, João Pedro. António Rodrigues: renascimento em Portugal. Dafne, 2007.

XAVIER, João Pedro. Arquitectura e Ciência - Antônio Rodrigues. Ciência em Portugal - Personagens e episódios. Porto, 2004. 